\title{
ADVANCES IN DIODE-LASER-BASED WATER VAPOR DIFFERENTIAL ABSORPTION LIDAR
}

\author{
Scott Spuler*1, Kevin Repasky ${ }^{2}$, Bruce Morley ${ }^{1}$, Drew Moen ${ }^{2}$, Tammy Weckwerth ${ }^{1}$, Matt Hayman ${ }^{1}$, Amin \\ Nehrir $^{3}$ \\ ${ }^{1}$ National Center for Atmospheric Research, Earth Observing Lab, Boulder, CO 80307, USA, *spuler@ucaredu \\ ${ }^{2}$ Montana State University, Electrical and Computer Engineering, Bozeman, MT 59717, USA \\ ${ }^{3}$ NASA Langley Research Center, Hampton, VA 23681, USA
}

\begin{abstract}
An advanced diode-laser-based water vapor differential absorption lidar (WV-DIAL) has been developed. The next generation design was built on the success of previous diode-laser-based prototypes and enables accurate measurement of water vapor closer to the ground surface, in rapidly changing atmospheric conditions, and in daytime cloudy conditions up to cloud base. The lidar provides up to $1 \mathrm{~min}$ resolution, $150 \mathrm{~m}$ range resolved measurements of water vapor in a broad range of atmospheric conditions. A description of the instrument and results from its initial field test in 2014 are discussed.
\end{abstract}

\section{INTRODUCTION}

Water vapor is a potent greenhouse gas which is heterogeneously distributed in the lower part of atmosphere. The distribution of water vapor influences dynamical and physical processes that drive weather phenomena, general circulation patterns, radiative transfer, and the global water cycle. Terrestrial boundary layers can be especially complex given the large amplitude of diurnal cycles and surface exchange complexities. A better understanding of its spatial and temporal distribution is required to support research, and to improve forecasts of severe weather and quantitative precipitation $[1,2]$.

Most instrumentation capable of accurately measuring water vapor profiles have either inadequate vertical spatial resolution (e.g., satellite observation) or insufficient temporal resolution (e.g., standard, twice a day radiosonde observations) to further our understanding. Laser remote sensing - provided by either Raman lidar [3, 4] or injection seeded Ti:sapphire-based DIAL systems $[5,6,7,8]$ - are capable of high vertical range resolution and continuous measurements; however, they are traditionally expensive devices to develop and operate. The instrument plus its operational cost is especially relevant since multiple devices - a network of profilers - are required to obtain adequate horizontal spatial resolution. Research applications generally require short term deployments of a regional scale network, whereas national forecasts require national networks. For example, in the continental USA, high-resolution vertical profiles of humidity at roughly 400 locations are required [1]. Therefore, a new generation of lower cost water vapor lidar - capable of safely, accurately, continuously, and autonomously measuring water vapor in the lower troposphere with high vertical resolution - is needed to lower the barrier to investment and enable a network.
Diode-laser-based lidar, with low power consumption via electrically pumped semiconductor transmitters - capable of operation for tens of thousands of hours without the requirement for water cooling - offer inherently lower initial costs, and lower operation and maintenance costs, when compared to traditional lidar systems. The first demonstration of a diode-laser-based WV-DIAL was in 2004 by Machol et al. which was capable of nighttime operation [9]. From 2009 to 2012 Nehrir et al. significantly advanced the field, particularly with respect to transmitter design [10, 11], and subsequently demonstrated the first diode-laser-based WV-DIAL capable of daytime measurements [12]. We have built on these seminal instruments and developed them further - towards a sensor that would be suitable for a national scale network - by improving eye-safety and reliability (e.g., reducing sensitivity to environmental temperature), and enabling accurate measurement of water vapor closer to the ground surface, in rapidly changing atmospheric conditions, and in daytime cloudy conditions up to cloud base [13].

\section{INSTRUMENT DESIGN}

The 'next' generation diode-laser-based WV-DIAL design uses a single frequency, single mode, distributed Bragg reflector (DBR) laser diode to seed an electrically pulsed GaAs semiconductor laser diode tapered amplifier. The transmitter has rapid frequency agility to alternate between online and offline wavelengths at rates up to $100 \mathrm{~Hz}$ and provides spectrally pure, narrowband amplified pulses. The pulsed laser output is shaped with a pair of axicons for efficient transmission through the inner portion of a shared telescope into an opto-mechanically stable and eye-safe annular transmit beam. The outer portion of the shared telescope is used to collect backscattered photons which subsequently pass through an ultranarrow multistage optical filtering. A critical part of the filter is a solid etalon designed to allow transmission of the online and offline radiation in adjacent cavity modes. A pair of photon-counting receiver modules - designed with narrow field-of-view for longer range, and wider field-of-view for measuring closer to the surface - are used to detect the backscattered photons. Each photoncounting module output enters a switch, which directs the signal to one of two channels on a four channel scalar card (two for each receiver) based on the transmits wavelength. The counts are gated and accumulated within the scalar card for $1 \mathrm{sec}$ and then read out by a computer. A schematic is shown in Fig. 1 which appears in the Atmospheric Measurement Techniques article by Spuler et 
al. [13] and contains a more complete description and specifications of the system.

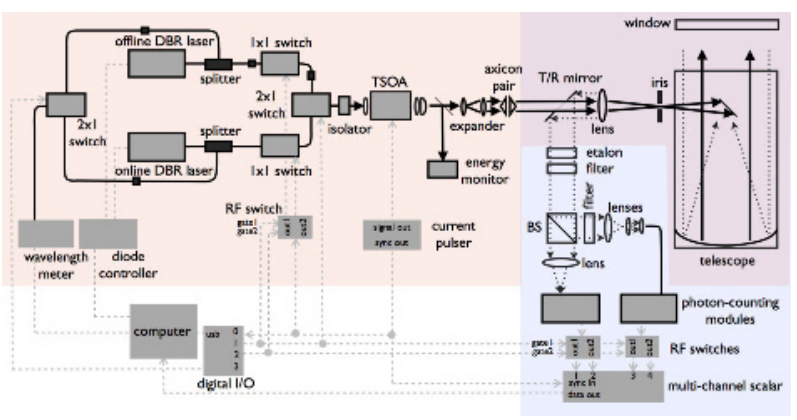

Figure 1. Schematic of the WV-DIAL system. $\mathrm{BS}=$ beam-splitter; $\mathrm{T} / \mathrm{R}=$ transmit receive; $\mathrm{I} / \mathrm{O}=$ input output. This figure appears in the Atmospheric Measurement Techniques article by Spuler et al. [13] and is used here with permission from Copernicus publications.

\section{FIELD TEST RESULTS}

The instrument was autonomously operated in Erie, CO, USA during the Front Range Air Pollution and Photochemistry Experiment (FRAPPE) between 1-July 2014 and 19-August 2014. The WV-DIAL operated near continuous for 50 days with an uptime of $>95 \%$. The shared telescope design proved stable - no re-alignments were made and the system had no measurable degradation in performance during the field campaign. Figure 2 shows the data from the project. The continuous observations of relative backscatter (top) illustrate the diurnal variation in the top of the aerosol layer and clearly identify cloud occurrences up to $12 \mathrm{~km}$ AGL. The water vapor profiles (displayed up to $7 \mathrm{~km}$ in the second panel) show data up to cloud base. The water vapor data illustrate substantial temporal variability and strong vertical gradients. The third panel shows background in counts per second $\left(\mathrm{C} \mathrm{s}^{-1}\right)$ for the near (red) and far (black) range channels. Count rates for the far range channel remain within the linear count regime for the photon counting module (Excelitas SPCM-AQRH-13) - below $1 \mathrm{MC} \mathrm{s}^{-1}$ for all conditions encountered during the project. The maximum count rate for the near range channel exceeds the linear count rate during daytime, bright-cloudy, conditions and these periods must be filtered out of the water vapor retrieval profiles. Ongoing studies to quantify the diurnal variability and to compare with radiosondes and GPS receivers will help to characterize the system. Continuous observations from this WV-DIAL will provide opportunities for both mesoscale and climatological characterization of water vapor structure and trends.

During FRAPPE, there were 2 nighttime soundings and 43 daytime soundings. The large number of daytime sondes allowed for comparisons with the DIAL during periods of high background solar radiation - the most difficult data collection conditions for the instrument. The mean relative error was less than $10 \%$ for all of the radiosonde comparisons, from $300 \mathrm{~m}$ to $4 \mathrm{~km}$ above ground level[13]. Therefore, data from this field campaign demonstrate the capability of the WV-DIAL to provide accurate measurements of water vapor in continual operation for an extended period of time in a variety of atmospheric conditions.

A national network for water vapor may include other thermodynamic profiling instruments such as passive remote sensors that measure water vapor and temperature which are useful at low ranges, close to the surface, but in general provide low vertical resolution. During FRAPPE, the WV-DIAL was collocated with a continually-operating passive infrared radiometer (AERI: Atmospheric Emitted Radiance Interferometer.) This is a passive infrared remote sensing instrument that utilizes an interference technique to retrieve atmospheric emitted radiance $[14,15,16,17]$. Starting with initial temperature and humidity profiles based on statistical models, an iterative solution to the radiative transfer equations is utilized to reproduce the measured atmospheric emitted radiance. This iterative solution provides the final temperature and WV profiles for clear sky conditions up to approximately $3 \mathrm{~km}$. During cloudy conditions, retrievals are sensitive to the cloud properties leading to larger errors in the temperature and WV profiles, so a separate measurement of the cloud base height is often required.

A preliminary comparison of the WV DIAL and AERI is included as Fig. 3. The AERI retrievals provide continuous profiles of water vapor (along with temperature which is not shown) up to $3.5 \mathrm{~km}$. The AERI profiles were retrieved every $10 \mathrm{~min}$ with a vertical resolution of $30 \mathrm{~m}$ at the surface decreasing to $600 \mathrm{~m}$ at $3 \mathrm{~km}$. The WV-DIAL data were processed with $1 \mathrm{~min}$ averaging and a vertical resolution of $150 \mathrm{~m}$ (300 m smoothing were applied to the data above $3 \mathrm{~km}$.) Note the comparable buildup in the moisture leading into 23 July. The increasing moisture values and depth are similarly observed by both instruments. The AERI and WV-DIAL are both limited in times of fog, such as that before 24 July. Both datasets show a similarly dramatic decrease in moisture just prior to 24 July. Perhaps this was caused by a frontal passage or other change in wind direction. Just prior to this abrupt change there appears to be an absolute humidity inversion in the DIAL data at $1 \mathrm{~km}$ AGL (note, inversions are not observable with passive remote sensors such as AERI). Again there is a comparable buildup in moisture quantity and depth at the end of the time series leading into 25 July. Further comparisons will be obtained through statistical methods for the entire FRAPPE time period. In the future we plan to investigate combining the DIAL water vapor and AERI radiances to see if the retrieved temperature profile can be improved.

\section{CONCLUSIONS AND FUTURE PLANS}

In summary, a next generation water vapor DIAL has been designed, constructed and tested which has the potential to enable a national scale network. The electrically-pumped semiconductor-based transmitter is 

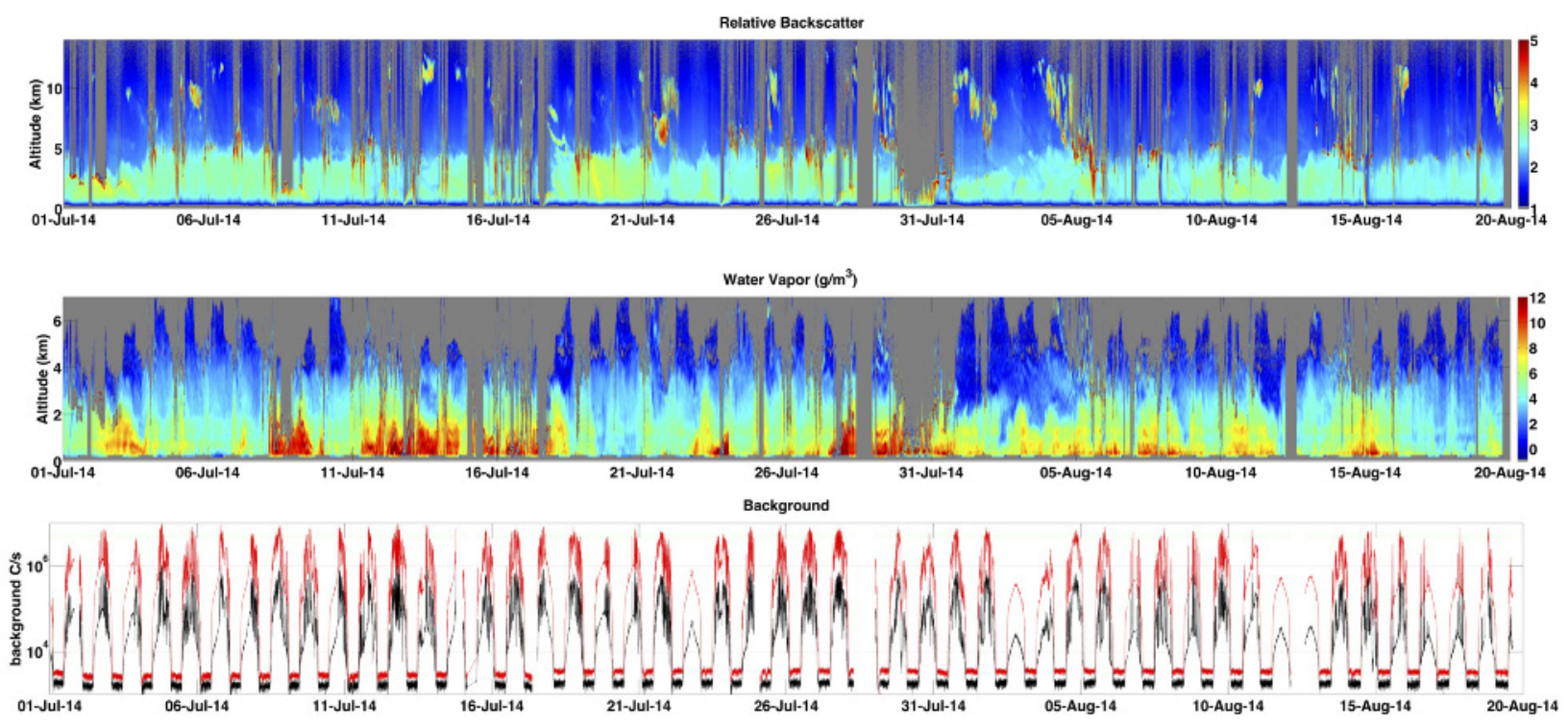

Figure 2. Fifty days of near continuous data collected 1 July to 20 August 2014. Top panel: 1 min, 150 m resolution relative backscatter from 0 to $14 \mathrm{~km}$ range for the far range channel. Middle panel: $10 \mathrm{~min}, 150 \mathrm{~m}$ resolution water vapor in $\mathrm{g} \mathrm{m}^{-3}$ from 0 to $7 \mathrm{~km}$ range for the far range channel - 300 and 600 meter smoothing were applied to the data from $3.0-5.25 \mathrm{~km}$, and above $5.25 \mathrm{~km}$; respectively. Bottom panel: background in counts per second $\left(\mathrm{C} \mathrm{s}^{-1}\right)$ for the near (red) and far (black) range channels.
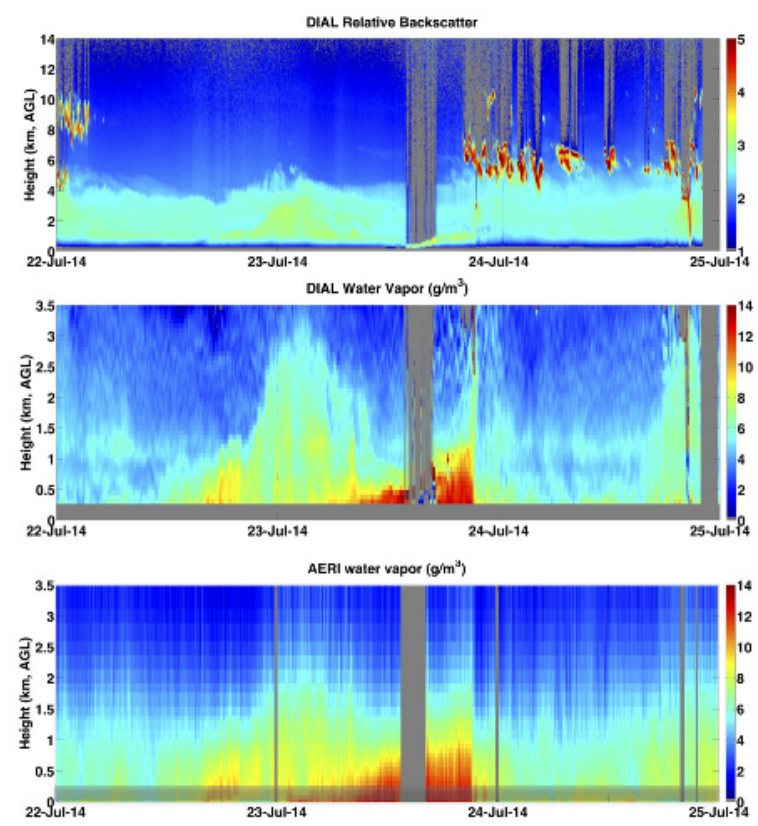

Figure 3. Comparisons between collocated WV-DIAL aerosol (top panel) and water vapor (middle panel) and AERI water vapor (bottom) 22-25 July 2014 during FRAPPE. Note the bottom 300 meters of the AERI image is grayed out for comparison purposes only. inherently low-maintenance, low-cost, and designed to be eye-safe at the exit port. It has the required characteristics necessary for the DIAL technique; rapid frequency agility with good spectral purity, and when combined with the ultra-narrowband multistage optical filters in the receiver, the system provides continuous profiles of water vapor with complete daytime coverage - including periods of bright clouds - with better than $+/-10 \%$ relative error from $300 \mathrm{~m}$ above ground level to $4 \mathrm{~km}$ (or cloud base, whichever comes first) with $150 \mathrm{~m}$ nominal vertical resolution and 1 minute temporal resolution. This lower cost lidar design is a significant step towards improving our understanding of the distribution of atmospheric water vapor.

\section{ACKNOWLEDGMENTS}

We would like to acknowledge Richard Carbone for helpful discussions pertaining to the atmospheric science applications, and Richard Erickson for technical support during development. We would also like to thank to Dave Turner for processing and supplying the AERI data used for the initial inter-comparison with the WV-DIAL. NCAR is sponsored by the National Science Foundation. The authors affiliated with Montana State University would like to acknowledge the support of the National Science Foundation grant number 1206166. 


\section{REFERENCES}

[1] National Research Council, 2009: Observing Weather and Climate from the Ground Up: A Nationwide Network of Networks. The National Academies Press, Washington, DC.

[2] National Research Council, 2010: When Weather Matters: Science and Service to Meet Critical Societal Needs. The National Academies Press, Washington, DC.

[3] Goldsmith, J. E., Forest, M., Blair, H., Bisson, S. E., and Turner., D. D., 1998: Turn-Key Raman Lidar for Profiling Atmospheric Water Vapor, Clouds, and Aerosols. Applied Optics, 37(21), 4979-4990.

[4] Turner, D. D., Ferrare, R. A., Brasseur, L. A. H., Feltz, W. F., and Tooman, T. P., 2002: Automated Retrievals of Water Vapor and Aerosol Profiles from an Operational Raman Lidar. Journal of Atmospheric and Oceanic Technology, 19(1), 37-50.

[5] Ertel, K., Linné, H., and Bösenberg, J., 2005: Injection-seeded pulsed Ti:sapphire laser with novel stabilization scheme and capability of dualwavelength operation. Applied Optics, 44, 5120 5126.

[6] Bösenberg, J. and Linné, H., 2006: Continuous Ground-Based Water Vapour Profiling using DIAL. In 23rd International Laser Radar Conference, pages 679-682, Nara City, Japan.

[7] Vogelmann, H. and Trickl, T., 2008: Wide-range sounding of free-tropospheric water vapor with a differential-absorption lidar (DIAL) at a highaltitude station. Applied Optics, 47, 2116-2132.

[8] Behrendt, A., Wulfmeyer, V., Riede, A., Wagner, G., Pal, S., Bauer, H., and Späth, F., 2010: Scanning differential absorption lidar for 3D observations of the atmospheric humidity field. In 25th International Laser Radar Conference, pages 1187-1190, St. Petersburg, Russia.

[9] Machol, J. L., Ayers, T., Schwenz, K. T., Koenig, K. W., Hardesty, R. M., Senff, C., Krainak, M. A., Abshire, J. B., Bravo, H. E., and Sandberg, S. P., 2004: Preliminary Measurements with an Automated Compact Differential Absorption Lidar for the Profiling of Water Vapor. Applied Optics, 43(15), 3110-3121.

[10] Nehrir, A. R., Repasky, K. S., Carlsten, J. L., Obland, M. D., and Shaw, J. A., 2009: Water Vapor Profiling Using a Widely Tunable, Amplified Diode-Laser-Based Differential Absorption Lidar (DIAL). Journal of Atmospheric and Oceanic Technology, 26(4), 733-745.

[11] Nehrir, A. R., Repasky, K. S., and Carlsten, J. L., 2012: Micropulse water vapor differential absorption lidar: transmitter design and performance. $O p$ tics express, 20(22), 25137-51.
[12] Nehrir, A. R., Repasky, K. S., and Carlsten, J. L., 2011: Eye-Safe Diode-Laser-Based Micropulse Differential Absorption Lidar (DIAL) for Water Vapor Profiling in the Lower Troposphere. Journal of Atmospheric and Oceanic Technology, 28(2), 131147.

[13] Spuler, S. M., Repasky, K. S., Morley, B., Moen, D., Hayman, M., and Nehrir, A. R., 2015: Field deployable diode-laser-based differential absorption lidar (DIAL) for profiling water vapor. Atmospheric Measurement Techniques, 8, 1073-1087.

[14] Turner, D. D. and Löhnert, U., 2014: Information content and uncertainties in thermodynamic profiles and liquid cloud properties retrieved from the ground-based atmospheric emitted radiance interferometer (AERI). Journal of Applied Meteorology and Climatology, 53(3), 752-771.

[15] Knuteson, R., Revercomb, H., Best, F., Ciganovich, N., Dedecker, R., Dirkx, T., Ellington, S., Feltz, W., Garcia, R., Howell, H., Smith, W., Short, J., and Tobin, D., 2004: Atmospheric emitted radiance interferometer. part II: Instrument performance. Journal of Atmospheric and Oceanic Technology, 21, 17771789.

[16] Knuteson, R., Revercomb, H., Best, F., Ciganovich, N., Dedecker, R., Dirkx, T. P., Ellington, S., Feltz, W., Garcia, R., Howell, H., Smith, W., Short, J., and Tobin, D., 2004: Atmospheric emitted radiance interferometer. Part I: Instrument Design. Journal of Atmospheric and Oceanic Technology, 21, 17631776.

[17] Feltz, W., Smith, W., Howell, H., Knuteson, R., H., W., and Revercomb, H., 2003: Near-continuous profiling of temperature, moisture, and atmospheric stability using the atmospheric emitted radiance interferometer (AERI). Journal of Applied Meteorology, 42, 584-597. 